\title{
Tweacher: New proposal for Online Social Networks Impact in Secondary Education
}

\author{
Sebastián Romero López ${ }^{\mathrm{a}}$, Habib M. Fardoun ${ }^{\mathrm{b}}$, Victor M. R. \\ Penichet ${ }^{\mathrm{a}}$, Jose A. Gallud ${ }^{\mathrm{a}}$ \\ ${ }^{a}$ Departamento de Sistemas Informáticos, Escuela Superior de Ingeniería Informática de Albacete, Universidad de \\ Castilla-La Mancha \\ ${ }^{\mathrm{b}}$ Information Systems Department, Faculty of Computing and Information Technology, King Abdulaziz University
}

KEYWORD

Online Social Networks

Tweacher

E-Learning

Secondary Education

Educative Web Tools

Collaborative Systems

User-Centered Design

\section{Introduction}

Social networks have recently been introduced in the lives of many people that were previously far from the Internet phenomenon. And, it is not uncommon to hear talks on the street about Facebook, and not necessarily among young people. The extraordinary ability to communicate and to connect people with networks has caused that a large number of people use them with very different purposes. They are used to find and engage with long ago lost friends, to discuss various subjects, all kinds of support causes, organize meetings of friends, former classmates or to publicize meetings and conferences, through which not only it provides details about the meeting, but people can confirm their attendance or absence of the event.

For that, the educational world cannot remain oblivious to like this social phenomenon, which is changing the way of communication between people. The education system works primarily with infor- mation, so there is no sense to use transmission systems and publication of the same based on those used in the early and mid-twentieth century, without incorporating what society already is using as part of their daily lives. Education must train people to what will work in ten years, not to emulate the way that worked for last ten years. Undoubtedly the potential communication of social networks is still to be discovered and should be studied more in depth [Fardoun, H. et al. 2011a]. It is in these moments when they begin to create networks for educational purposes and, without doubt, in the coming months there will be interesting developments in this regard.

Social networks have become a virtual environment where many people converge. The exponential growth of social networks today have turned these sites into an interesting analysis tool to find usages, customs and origin of many users that comprise them. Some of these social networking services like Facebook, among others, are used by many universities in the world to publish their works, videos, resources and projects, to be criticized and evaluated by the 
community, and this become of a great support to teachers. Using this tool is increasingly common among humans; hundreds of thousands of users worldwide have experienced the use of Facebook as a tool for the development of social communities. The impact of social networks like Facebook or Twitter is growing stronger worldwide. However, to think about the role of teachers in our time, it would be possible from a contextualization: insert the teacher's role in the context of the knowledge society.

Endless are the number of hours, news, energy that is now being used by the online social networks (hereafter OSN), adolescents being one of the main social groups that depend on these systems to communicate with their peer group and acquaintances. But how can it is possible to work with a tool that has many friends, messages, photos, videos! Which suppose too many distracting to the students, and would be contrary to achieve the objective sought. Some of the research considered in this paper study is Facebook as a tool for college students with positive results. But for teenage students, is responsible enough to use the educational online social networks? Or to use these environments, the student, must be taken out from the OSNs that use commonly, and use others where there are no many elements that make the students lose concentration while they are performing their tasks.

The initial hypothesis to be validated: social networks can serve as an educational tool, acting as a motivator and enabler of social capital in education during adolescence (age range 12 to 18 years, with reference to the Spanish system, named as compulsory secondary education "E.S.O"). The paper is organized in five sections: Social networking in education, the analysis of one of the major educational OSNs, the field work which discusses the use of the OSNs by students, Tweacher application, and it ends with conclusions and future work.

\section{Social Networks within Education}

This section introduces the basic concepts of the OSN, a series of research on its application in education, and the beginnings of the union of these two fields.

\subsection{OnLine Social Networks}

According to Danah Boyd [Boyd, D. et al. 2007], OSNs are Websites that give users a range of services based on Web technologies that allow individuals to: build a public or semi-public profile with relationships system, to have a list of other users with whom they share a connection, and finally, view and navigate through the list of users' connections with those who share a connection in the system. The shape and nomenclature of the connections listed above vary from one social network to another. What makes the OSNs unique is because they make possible for users to manage and make visible their own social network, not because they allow users to meet others in the network. Normally connections on OSNs are between individuals who have "latent ties", Haythornthwaite [Haythornthwaite, C. 2002], and that have some offline connection. In many OSN, users are not looking to expand their network of contacts (such as LinkedIn [LinkedIn, 2012]), but they communicate with people they already knew prior to their entry into this OSN.

The most widespread and used features by OSNs users are: uploading and sharing photos and videos, comments on other profiles, friends and private messages between users. Users of these sites also share a number of documents and communicate with each other.

\subsection{Computer applications for learning support}

Arguably, the first steps of social networks in education correspond to Moodle [Moodle, 2012], at least in terms of the widespread use of the platform. Moodle is a project designed to support a social constructionist framework of education. It is distributed as free software (GNU). Moodle is copyrighted, but user can copy, use and modify Moodle if they agree to distribute the source code to others, without removing the original license and copyrights. The design and development of Moodle is based on an educational philosophy called "social constructionist pedagogy". Moodle can be considered as one of the first OSN focused on education, because it has one of the OSN main features.

Some basic questions that the Web Systems share with education is: Who are the students? What student's intentions and behaviours will be supported by the system? What devices students will use? E- 
Learning platforms solve these questions based on five different aspects: purpose, use, content, functionality and presentation. Based on the information taken from [Fardoun, H. 2011], in the following sections, EdModo [EdModo, 2012] is discussed.

Moreover, in [Fardoun, H. 2011], we found comparison of the educational and technical aspects of the main electronic learning platforms: Blackboard Academic Suite 8.0, Claroline 1.8.1, Ecollege, WebStudy Course Management System, Atutor 1.5.4, Moodle 1.9 , and JoomlaLMS. They compare various aspects like: productivity, communication, participation of students, administration, content development, licensing, and the required hardware and software. Highlighting after such detailed analysis the communication and motivation as key factors in the student learning process, therefore the student should not be or feel isolated. Finally the authors sort the platforms in two types: Those that are not attractive for most users, but at the same time they are fully developed and have most of the functionality needed by teachers and students. Those that are highly attractive, but do not provide a variety of services.

\section{Edmodo Analyses}

This section discusses the online social network tool Edmodo [6], an educative social network. The following we describe its implemented functionality, the non-permitted and weaknesses points. Based on the presented aspects in the sub-section 2.2, the purpose of this tool is the informal education, and to be used as an educational system and its contents are usually related to different subjects of the students.

\subsection{Edmodo Main Features}

In this sub-section we analyse the main features, which are available on the Edmodo platform. It will be discussed some specific functions of communication, organization, file sharing and educational tasks.

The initial interface that the tool offers for teacher and students is very similar, but with some extra functionality in the teacher side, like: The first action offered by the tool for teachers is to create the class groups, as it is required. Each group has a number of options that can be managed, if the user has a teacher role. The teacher can view the group members (students and teachers), he can archive and / or delete a group if it is necessary. From the public view, we may highlight that the teacher can decide the comments to be shared with people who are from outside of a specific group.

In terms of communication that is performed by using a board, the teacher could present it, to an entire group or as a private individual for each student. The teacher has four types of communication: (1) messages, (2) alerts, (3) assignment (or a task which can be rated later) and (4) vote. It is possible to add to each communication element: a file, a link (URL) or an existent item from the digital library. It has a section called "Who?" Where users can send messages in deferent ways to users: individual (private), students group, teachers and parents.

In the student side, the communication options are more limited than those of teacher, where they only have the option message, and they can only communicate in two ways: (1) with the entire class in public way or (2) in private way with the teacher.

Both teachers and students have access to a calendar, depending on the classes they teach, and the students to the classes to which they have joined where also they can view the deliverables or dates set by the teachers. These management features convert the Edmodo tool in a great tool for organizing and planning.

For storing and sharing files, there are two points of view in the Edmodo platform: The teacher view, where he can share folders with material for one or more of his classes, and the student view, with a space of $100 \mathrm{MB}$, to store his files and/or class assignments.

Finally, from the user profile, other users can see (if they are connected to him): public activity, connections with teachers (if the user has a teacher role) their colleagues, besides seeing there school and classes that they manage or in which they participate.

\subsection{Weaknesses and not allowed Features}

This section describes the unpermitted or unimplemented functionalities within the platform and its weaknesses. Studding this information is helping us in the implementation process of our own OSN tool, which we called Tweacher. Tweacher is an OSN for educational purposes whose target audience is very similar to Edmodo. The weaknesses and the not allowed features we discover in Edmodo are: 
- It has no option to send private messages between students, avoid forgetfulness, communication between students occurs globally.

- In the communication part, it has not implemented a chat tool. While, many other social networks (like Facebook, Tuenti, and Myspace) implement a kind of chat area for users.

- It does not work with photo albums and tags like other social networks. It works with generic file type, and do not allow the action of tagging them.

- It does not implement any kind of page in which the user can see the subject structure (index).

- Edmodo structure facilitates informal education; however, the order of the content of the courses and materials is not entirely clear.

- The functionality backpack, where students can save files that cannot be accessed by teachers, can be a weak point, since students could use it to save improper files

\section{Fieldwork: Using On-Line Social Networks by Students}

This section presents a field study, which reflects the big use of the new technologies and social networks by high school students. Also, it highlights a set of advantages for their application in teaching. The field study is focused on Tuenti [Tuenti, 2012] and Facebook. First, we present the results obtained through an anonymous questionnaire given at three centres of the community Castilla-La Mancha, Spain (two secondary and one primary education centres). Next, we will discuss the main findings of this field study conducted during the last two academic years and applied over 425 students (381 secondary education and 64 of primary one).

\subsection{Anonymous questionnaires on the use of social networks}

We address first the results in secondary education talks (12 to 18 years, questionnaires to students from $1^{\circ}$ to $4^{\circ}$ of the E.S.O):

In the academic year $2009 / 2010$, students carried out 282 questionnaires. The result was that, $88 \%$ of students use online social network Tuenti, taking into consideration that according to Spanish law it is illegal for children less than 14 years to use it. Well, the surveys were conducted at the beginning of 2010, so the students were born in 1996 and 1997 (which are $44.7 \%$ of respondents). Those are violating the terms of use of this tool, because they are minors, in particular $86.7 \%$ are registered on the social network Tuenti.

Given that $88 \%$ of the students use the Tuenti social network, from this percentage we extracted other interesting facts like: The average number of "friends" is 198.9 in the profile of each student. The average time spent connected to the Tuenti social network is 1 hour and a half per day. With regard to the social network Facebook, we have: $43.4 \%$ of respondents are registered in this social network.

We can highlight $88 \%$ of respondents who use the social network Tuenti as $61 \%$ of them are connected to the social network for more than one year and $70 \%$ have more than 140 "friends".

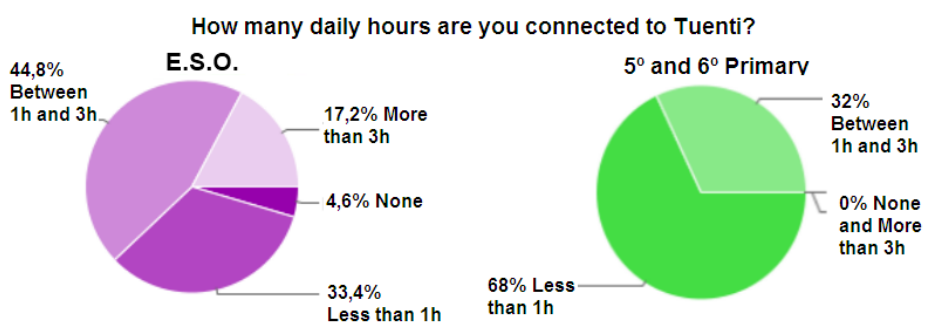

Fig. 1. Hours per Day using Tuenti, course 2010 / 2011

$17.2 \%$ recognized to consume more than 3 hours use per day (Fig. 1 left.). While when we refer to harassment, the data is not worrisome since $3 \%$ have felt bullied at some point. With regard to Facebook, $63 \%$ of the students are registered on it, and the average number of friends is smaller to the average number of 
friends on Tuenti. The most alarming, and was not taken into consideration in the previous academic year's study, is whether the parents are concerned about what their children are doing using the OSNs (Fig. 2 left.). 55\% respond positively to this question. This indicate that $45 \%$ of parents who are not interested and do not ask their children about the purpose behind using these new communication environments.

For primary education, the questionnaires were presented to 64 students in various lectures in $5^{\circ}$ and $6^{\circ}$ of the primary school, during the academic year 2011. We obtained the following results: $43.5 \%$ of students use Tuenti which suppose a high number, taking into consideration the prohibition that the
Spanish authorities have with respect to this matter. On the other side, $52 \%$ of parents worry about what their children do in the OSN (Fig. 2 right), a slightly lower percentage com-pared to E.S.O parents. This slight difference would be probably because some of the children were not yet interested to register in OSNs. Statistics showed that $1.8 \%$ of respondents felt harassed using OSNs. And finally, we remark that the number of "friends" and hours of use per day is significantly lower than the results obtained in secondary education. Only 25\% have more than 140 "friends" and $68 \%$ spend less than an hour online per day (Fig. 1 right).
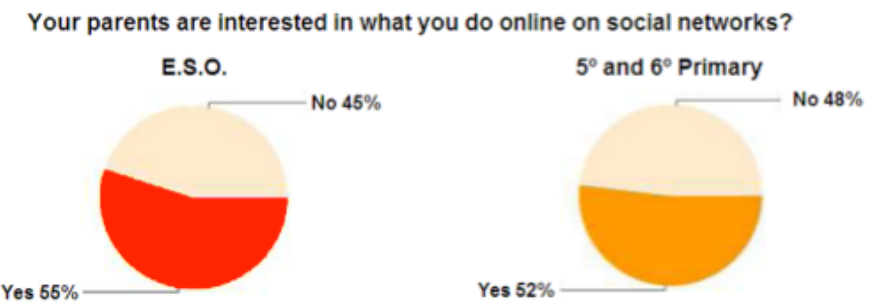

Fig. 1. Interest of parents for the use of ONSs, course 2.010/11

We can say that, this trend of interaction through online social networks will continue in the future as the new generations make a high use of these networks because of being already an important part of their lives.

\subsection{Analysis of the anonymous questionnaires results on social networks}

The reason for this analysis is that, in many cases where students do not have online social networks are because of the parents' controls, and the Spanish government that does not allow access to such services for citizens less than 14 years.

After analyzing this data, we can say that it is obvious where adolescents spend their time and what habits they have. Therefore, using this tool, as an educational, by students who know in depth and make

use of their free time, can raise the motivation levels with respect to certain subjects. Although the learning curve of using the educational tools will be very quick, it would not reach the common social networks' level.
Could positive academic results be obtained through online social networks? The answer is yes, demonstrated by the results of the research presented next. In [Yan Yu, A. 2010] research the impact of individual use of these online social networks from an educational point of view. This paper takes into consideration two processes of socialization such as: social acceptance and cultural adaptation, showing that an online social network in these processes help positively influence to academic outcomes. Thereby, it demonstrated the positive influence at the university level. So, obtaining positive results at the level of secondary education is one of the objectives of this work, considering that at this age, students need more control (from parents and teachers) than that at the college age.

\subsection{Edmodo in a real environ- ment}

For this study we have worked with a group of 20 students in the "information technology and communication" subject of 1 bachelor's degree, and 38 students divided into two classes of $4^{\circ}$ E.S.O in the "computer" subject during the months of February 
and March 2011. With respect to 1 bachelor's degree we highlight the following: We have dedicated and skilled jobs through the platform, there have been an informal communication between student and teacher and student-student. It was also proposed sharing of current information with the rest of the group. The study has been very successful. It was offered to teachers of 1 bachelor's degree the option of working with students using Edmodo. Only 14.3\% seemed interested and responded positively (a possible weakness of this type of platform, teachers who feel unprepared or interested).

We conducted a survey with students obtaining the following data: Are OSNs interesting to use for educational purposes? $68.75 \%$ answered yes, $25 \%$ No and $6.25 \%$ indifferent. Would you like to work with Edmodo in other subjects? $66.7 \%$ said yes, $33.3 \%$ indifferent and $0 \%$ No. At the end, we highlight three data: $95 \%$ of students have participated in Edmodo, $70 \%$ actively and continuously (at least one publication a week), and $50 \%$ of students have used the platform in non-lecture hours.

The results obtained during $4^{\circ}$ of the E.S.O haven't being as good as 1 bachelor degree, because its use by students was not as expected and their collaboration was proved to be too far below expectations. While bachelor students add news of every kind and discuss with them mates about them in an educate way, E.S.O. students just add contents to the wall of Edmodo when the professor have asked for it. Seeing the data of the sub-section 4.1 of this article the low participation in E.S.O. students was unexpected, ¿Which is the main problem? The difference in age is just one year; E.S.O. is compulsory education while bachelor isn't, differences between social groups and their behaviour as groups ¿could be them some explanations? The unique way to resolve this question is by doing more field-research.

As a consequence of this field-research this year five professors more are using Edmodo at their classes, even with the results of E.S.O. students want new tools during their lessons. In this process we are learning how to teach using these new platforms that the research in e-Learning gives us.

\subsection{Others High Schools at a click of distance}

In addition to what mentioned in the previous section Edmodo work between two classes of 1 bachelor degree in two different high schools (of Castilla-La Mancha). A new Edmodo group was created and it was supervised by two teachers in charge (one of each high school) established a set of rules of good use, otherwise teachers can use the option "reader" for students with bad behavior. The group was of 41 students in the "information technology and communication" subject of 1 bachelor's degree. They were allowed to name the group to feel unit holders. And the main use was to share news and comment on technology among students of both high schools. The high school students who had been working longer with Edmodo were more active while their counterparts from the other school they were less (with certain exceptions).

Perhaps this extra motivation of being able to interact with peers from another part of his country was what allowed us to obtain better results with bachelor students.

\section{Tweacher: A Pilot Online Social Network for Education}

This section will present Tweacher, a social application for educational use. It will starts from the concept of micro-blogging and will be added, functions of an Learning Management System (LMS), such as subscriptions to courses or subjects to perform management tasks for students, qualification of these, message board and course material, among others.

With the creation of this tool, we try to exploit the potential shown in the previous section of the article.

Ultimately, Tweacher is a complementary platform that can be used as a tool in the educational process. In which we try to make a different approach to the one made by the creators of Edmodo [Edmodo, 2012].

\subsection{Tweacher Architecture: Software and Hardware}

The application architecture will have the model client / server, see Fig. 3. 


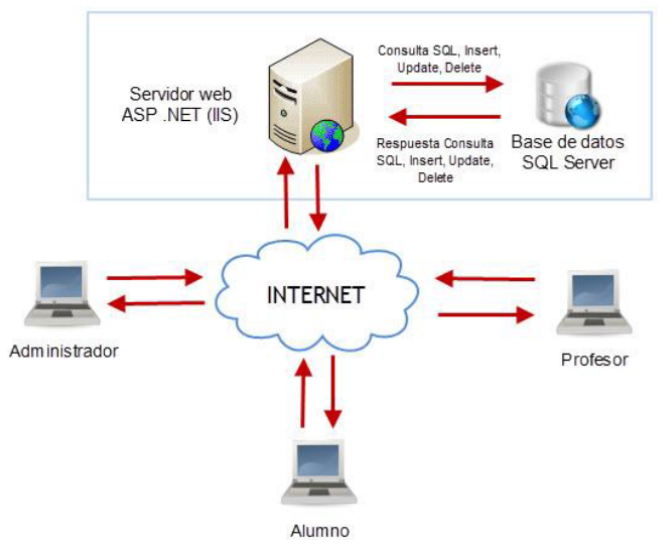

Fig. 3. Tweacher Hardware Architecture

For the function and operation of the present prototype, it was necessary: a Web Server and a Database. In this case, both servers are located on the same machine. The Web Server resolves the made requests, and interpret the code for the generation of
Web pages that belongs to the application. The database server has all the tables and the relationships between them, which will be linked with the application to manage the participants, groups, micro-posts and tasks, etc.

We have three types of users involved in the system, which is consistent with the existing application roles: administrator, teacher and student. These may be connected to the system via the Internet, making requests to the server, and this in turn is connected to the database, as needed, to solve some of these requests.

For the implementation of the prototype, an ASP.NET software technology has been used, from Microsoft with C\# language, to create dynamic Web sites. The database was created using SQL Server 2010. In Fig. 4 we can see the system that composes the software architecture of the prototype, which in turn is divided into sub-systems.

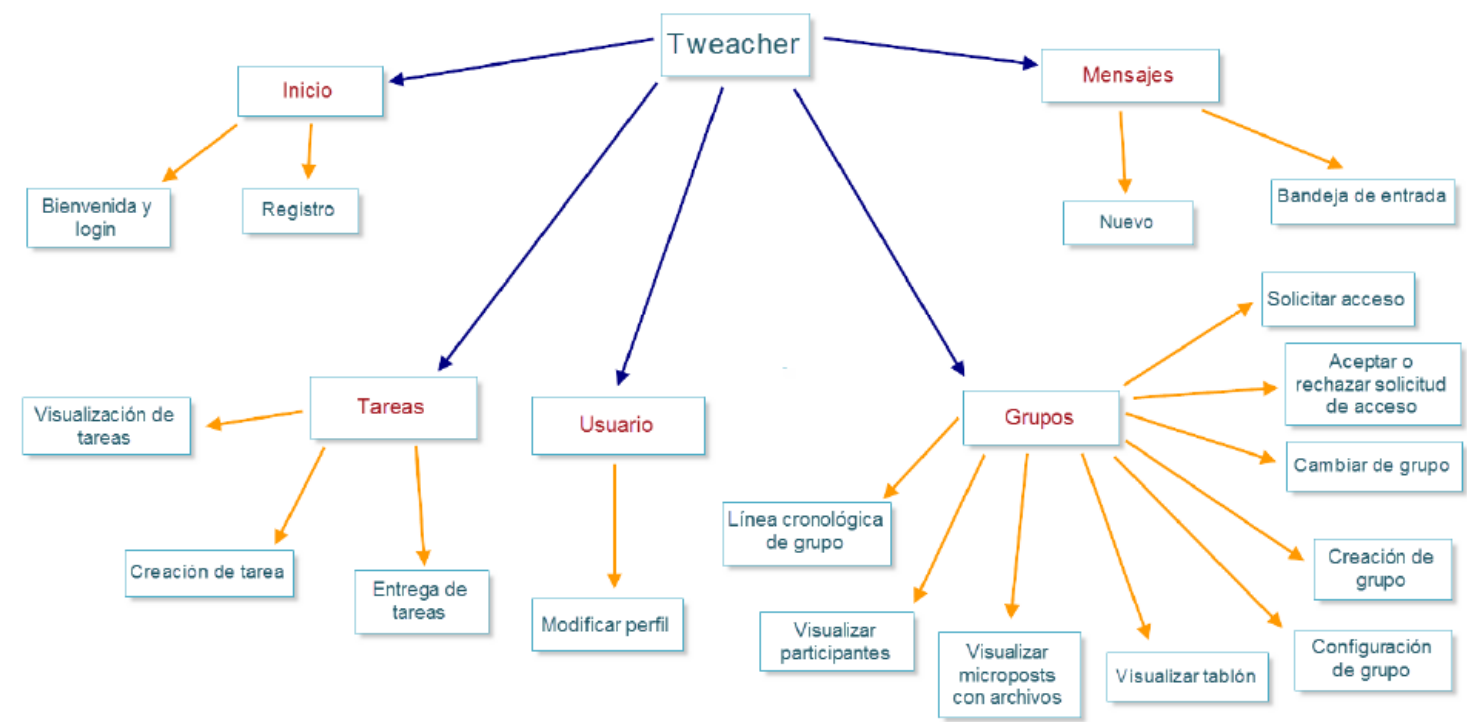

Fig. 4. Tweacher Software Architecture

Tweacher is divided into the following subsystems:

- Home: manages the login and user registration. It is a requirement to be registered and logged in, to start using the application.

- User: manages the user's personal information, giving this option to modify your profile.

- Messages: manages private messages between users. Users have the option to create a new message, or to consult those he has sent in his inbox.
- Groups: is the largest subsystem, for being the backbone of Tweacher. For each of the groups the user has a timeline or temporary messages, which he can view. In addition, all users will be able to view the participants, the board and the messages to which the user has attached a file. Another option is to change the current group in which he is belongs to. This subsystem also manages to create a new group by a teacher or administrator, to introduce users to the new group (if they have previously requested access) and configure it. 
- Tasks: manages the tasks of a group and everything connected with it, starting with its creation, delivery and display.

\subsection{Prototype and Key Features}

The prototype is designed following an iterative incremental development, focusing on the user interface, according to the initial requirements that were raised, and have been refined in later phases, not only in terms of interface, but also in functionality and User Centered Design [Fardoun, H. et al. 2011b] [Fardoun, H. et al. 2012]. In the first iteration of the prototype stage, we performed a navigation prototype on paper, which served as a starting point in the design.

In the second iteration we created a low-fidelity prototype, a beta (Tweacher 1.0), which gives us overall information of the application, without going into too much detail. In the prototype shown with GUILayout tool [Blankenhorn K., 2004], a model simulating is done with pencil and paper. It gives us information, in first instance; of the containers that we use and which part will be placed on them in the main screen.

Fig. 5. shows the initial screen after the third and final iteration:

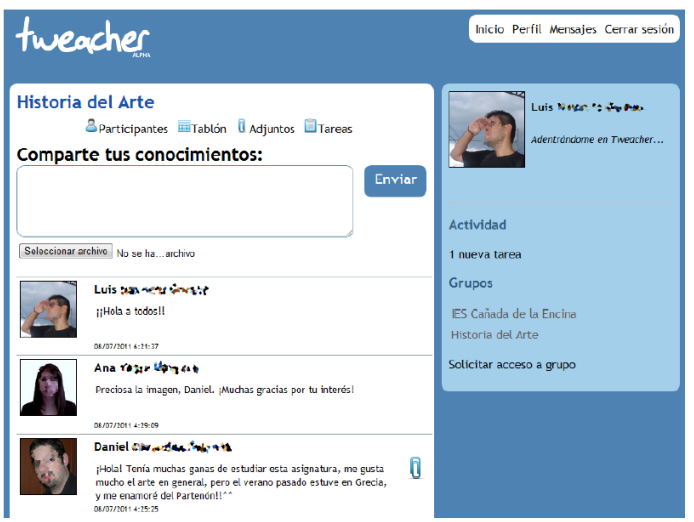

Fig. 5. Tweacher Initial Page

Figure X.3 shows the zone of a student, who is using Tweacher. Next we details each of the main parts:

On the right side of the head we find the user account control area, where it has access to the user profile settings, messages and the end of the session.

In the left part of the Figure their are two different parts:

- First, a top menu, depends of the group to which the user belongs, he can view the participants' list to which he can access: the board, the group of messages with attachments, tasks and configuration of the list (in this case he should be the owner). At this stage of the design, we introduced the "Board and attachment" element in the group.

- On the other hand, the body changing varies depending on what is selected in the top menu. In this case, the user sees the timeline of the group and the message area where he can post his messages, as to attach a file if the user wishes.

- As with any Simple Notification Service (SNS), the application notifies the prompts regarding the recent activity, since the user last access. These alerts include: new messages, new tasks and new access requests.

The "Groups" section indicates the groups to which the user belongs. The user can click one of the groups to change his timeline from the current one, to the one he select. Later, the user can view the participants, the board, and configuration tasks for it (if he is the creator).

The last element common is: "Request access to group", where both the student and the teacher can perform it. The teacher has more options, these are:

- Create a new group and become its manager.

- Check access requests to accept or reject them.

- Create a new task in the groups in which he is the creator

\subsection{Tweacher Test}

At the beginning of the third iteration, during the design and implementation phases of the prototype, an evaluation process was performed with real users, to ensure the user-centered design of the application.

The evaluation was performed for the first 11 Bachelor students, of a secondary center of CastillaLa Mancha, Spain, who previously have used Edmodo in their classrooms. The evaluation method was chosen through surveys, which reflect the degree of agreement on a scale of 1 to 5 , with 1 being "less agree" and 5 represents "most agree". The students performed tasks that included: Making a record in the application, apply for membership in a group, write messages on the timeline of a group, check the remaining tasks, see the private messages and logging.

And some of the results were: Overall, students believe that the difficulty of creating new user is low. 
Students found the tool intuitive and easy. $90 \%$ of students believe that this application serves as a support tool in learning. Which make us; therefore, conclude that the development of the tests was positive.

\section{Conclusions}

This work is a study done for the implementation of a tool similar to Edmodo, whose name is Tweacher (Twitter + Teacher). In this study, we try to cover the weaknesses found in the previous tools (sub-section 3.2) and add extra functionality to improve the teaching-learning process through such tools.

With the presented data in section four, we can say that the use of OSNs in educational environment can be positive. And for its implementation as an educational tool, it takes time and especially for its involvement by the faculty.

We can conclude then that Tweacher might be an option as a new educative social network to be used in the classroom, in our case trying to improve tools previously studied and worked as Edmodo.

A possible future improvement could be by establishing the use of counters to warn parents and teachers about the overuse of the tool by students. We did not analyse the parental control features available on Edmodo. It would be interesting to analyse and make a formal proposal on the possible ways of control that parents may have.

\section{Acknowledgment}

This research was partially supported by the project of the Ministry of Education and Science "CICYT TIN2008-06596-C02-0", the regional projects of the Regional Government of Castilla-La Mancha "PPII10-0300-4174" and "PII2C09-01851030 ". Thank you very much for teachers and students from the high schools of Castilla-La Mancha who participated in this research.

\section{References}

[Blankenhorn, K. 2004]

[Boyd, D.et al. 2007]

[EdModo, 2012]

[Fardoun, H. 2011]

[Fardoun, H. et al. 2011a]

[Fardoun, H. et al. 2011b]

[Fardoun, H. et al. 2012]

[Haythornthwaite, C. 2002]
Blankenhorn, K. (2004). A UML Profile for GUILayout. Last access: $4^{\text {th }}$ of July 2011, Link: http://www.bitfolge.de/pubs/thesis/

Danah Boyd and Nicole Ellison (2007, October).

"Social Network Sites: Defi-nition, History, and Scholarship." Journal of ComputerMediated Communica-tion, 13 (1), article

EdModo red social on-line educativa,

Last access: June 2012. Link: http://www.edmodo.com

Fardoun, H., 2011. PhD Thesis.

ElearniXML: towards a model-based approach for the development of e-learning systems. University Castilla-La; Mancha. Spain

Fardoun, H. M., Alghazzawi, D., López, S., Penichet, V., \& Gallud, J. (2012).

Online Social Networks Impact in Secondary Education. In International Workshop on Evidence-Based Technology Enhanced Learning (pp. 37-45). Springer Berlin/Heidelberg

Fardoun, H. M., Lopez, S.R., Villanueva, P. G. December 2011

Improving E-Learning Using Distributed User Interfaces.

Distributed User Interfaces. Human-Computer Interaction Series, 2011, 75-85, DOI: 10.1007/978-1-4471-2271-5_9. Springer London, ISBN: 978-1-4471-2271-5.

Fardoun, H. M., Daniyal M. Alghazzawi. March 2012

Student/Teacher-Centered Design: The Basis for the Development of e-Learning Systems.

5th Conference on eLearning Excellence in the Middle East.

International Journal of Computer Science and Information Technology (IJCSIT), March 2012, Page: 69-80, ISSN: 2091-1610. Dubai, United Arab Emirates

Caroline Haythornthwaite (2.002) Strong, Weak, and Latent Ties and the Impact of 
[LinkedIn, 2012]

[Moodle, 2012]

[Tuenti, 2012]

[Yan Yu, A. 2010]
New Media. The Information Society: An International Journal Volume 18, Issue 5, 2002, Pages 385 - 401 DOI: 10.1080/01972240290108195

LinkedIn red social on-line professional, Last access: June 2012.

Link: http://www.linkedin.com

Moodle 2.0.2. Last Access: 4th Abril of 2011.

Link: http://moodle.org/

Tuenti red social on-line.

Last access: June 2012. Link: http://www.tuenti.com

Angela Yan Yu, Stella Wen Tian, Douglas Vogel, and Ron Chi-Wai Kwok. 2010.

Can learning be virtually boosted? An investigation of online social networking impacts. Comput. Educ. 55, 4 (December 2010), 1494-1503. DOI=10.1016/j.compedu.2010.06.015 